\title{
The use of multi-criteria decision analysis to define and evaluate socially responsible investments
}

\section{Lieven De Moor Tim Verheyden}
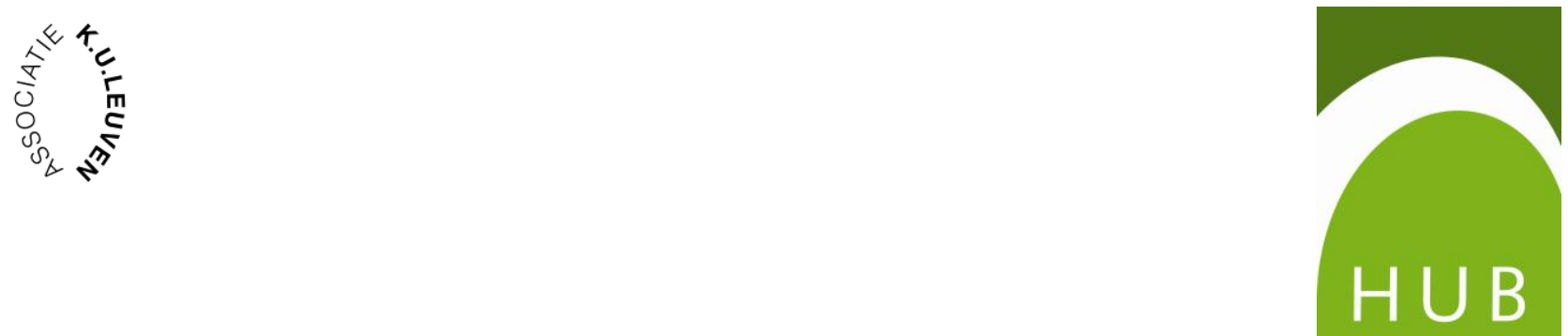


\title{
The use of multi-criteria decision analysis to define and evaluate socially responsible investments
}

\author{
Lieven De Moor* \\ Vrije Universiteit Brussel \\ Hogeschool-Universiteit Brussel
}

\author{
Tim Verheyden ${ }^{\dagger}$ \\ Hogeschool-Universiteit Brussel \\ KU Leuven
}

August 26, 2013

\begin{abstract}
The practice of socially responsible investing (SRI) has evolved over the last decades. Originally being a niche strategy followed by few investors, it now represents a significant part of the assets under management. The question remains, however, whether SRI funds out- or under performs conventional funds. After summarizing views from both sides of the SRI performance debate, we present four challenges that are facing the further development of SRI. Given its ability to take into account the multiple dimensions of social responsibility, we point to multi-criteria decision analysis (MCDA) as the methodological framework that could help overcome these challenges. A first group of challenges calls for the development of a general social performance indicator, which can score and classify mutual funds based on their social performance. Another challenge requires a transparent tool for retail investors interested in SRI to learn about their personal SRI preferences. Reviewing the three schools of available MCDA methods, we present a concrete approach for future research in building such a social performance indicator and a retail investor tool for SRI.
\end{abstract}

Keywords: socially responsible investing; mutual funds; multi-criteria decision analysis JEL-codes: A13, C44, G10, G11, G12

\section{Introduction}

Socially responsible investing (SRI) has experienced a rapid growth over the past decade, reflecting the increasing awareness of investors to environmental, social and governance (ESG) issues. Different definitions of SRI have been suggested. Instead of looking at one static definition, we might consider the development of the SRI concept (Renneboog, Ter Horst, \& Zhang, 2008). The first generation of SRI simply consisted of the application of negative screens to the investment universe. In considering different investment opportunities, some criteria are established to screen out "sin stocks" or companies that are in discordance with a set of moral and/or ethical principles. In the second generation of SRI, the focus was more on adopting positive screens and a best-in-class approach. The combination of both positive and negative screens led to the third generation of SRI. The fourth and most recent generation of SRI includes shareholder activism, next to the application of positive and negative screens.

The origins of SRI go back to the moral principles adopted by religious organizations in considering investment alternatives. In the mid 1700s, the founder of Methodism, John Wesley, stated that the use of money was the second most important subject of New Testament teachings (Social Investment Forum, 1999). The Quakers, or Religious Society of Friends, refused to invest in weapons and slavery. Modern day SRI finds its origin in the politically challenging climate of the 1960s, when concerns were raised over the Vietnam war, the cold war, equality for women and civil rights. These concerns served as an important impetus for

\footnotetext{
*Warmoesberg 26, 1000 Brussels, Belgium, lieven.demoor@hubrussel.be

†Corresponding author, Warmoesberg 26, 1000 Brussels, Belgium, tim.verheyden@hubrussel.be
} 
the concept of social responsibility. Protests against nuclear power further enforced the new movement on social responsibility through the 1970s. The definitive breakthrough for socially responsible investment came with the massive worldwide protest against the racist system of apartheid in South Africa. In recent years SRI has moved from niche to mainstream (KPMG \& ALFI, 2013), as issues like global warming, the Kyoto Protocol, corporate governance, and community investing have gained significant attention from investors around the world. In addition, governments in western countries have taken many regulatory initiatives to stimulate SRI. Both elements create a pro-SRI environment in which SRI will continue to grow and establish its relative importance as an asset class (Renneboog, Ter Horst, \& Zhang, 2008). According to the Forum for Sustainable and Responsible Investment (2012) a little more than one out of every nine dollars (11.3\%) under professional asset management in the United States is invested in the SRI universe. At the start of 2012, SRI assets managed by professionals stood at $\$ 3.744$ trillion, a rise of more than 486 percent from the $\$ 639$ billion in 1995. Over the same period, the broader universe of assets under conventional professional management rose only 376 percent. The latest SRI study by Eurosif (2012) demonstrates similar results. The combined growth of SRI strategies has outperformed the conventional market in Europe, despite the current financial turmoil.

The central aim of this paper is to open up alleys for future research, by pointing out some outstanding challenges in the SRI field and by presenting a possible methodological approach to address these challenges. We review the debate on the financial performance of SRI funds and argue that the current dichotomic classification of a funds' social responsibility lies at the heart of the current controversy. In order to enrich the academic debate, we see a need for a proper framework to select, evaluate and categorize SRI funds in a more nuanced and continuous way. Such a framework can also benefit governmental agencies in regulating the SRI market and commercial banks in developing new SRI products. Additionally, from the 2012 Eurosif SRI study, we see that the European SRI retail market is particularly underdeveloped. The main part of SRI investments and growth come from institutional investors. One of the reasons is a lack of transparency for retail investors and the proliferation of different methods to determine the social performance of mutual funds. Clearly, there is a need for a transparent yardstick allowing retail investors to determine the social responsibility content of their investments. Also, retail investors need some guidance in getting to know their personal preferences with regard to social investing. For all of these challenges, we point to multi-criteria decision analysis (MCDA) as a potentially interesting methodology to help define and evaluate the social performance of mutual funds. We review the different schools of MCDA methods and present a concrete approach to apply MCDA to the modern challenges facing the further development of SRI as an asset class.

In section 2 we provide a brief overview of the SRI performance debate. Section 3 identifies four challenges for the SRI field. Section 4 reviews the different classes of MCDA methods and shows how these methods could be helpful in addressing the issues pointed out in section 2 . The last section concludes.

\section{The SRI performance debate}

As several review papers on the SRI performance debate have been written (e.g. Margolis \& Walsh, 2003; Orlitzky, Schmidt, \& Rynes, 2003), it is not our aim to provide a complete overview of earlier research on this topic. Rather, we present a summary of the two fields where the debate has been spurred and the different lines of reasoning that have been developed.

In strategic management science, the debate on corporate social versus corporate financial performance goes back to the opposing views of Friedman (1970) and Freeman (1984). In a New York Times Magazine article, Friedman (1970) makes the case for shareholder theory, which states that the sole responsibility of businesses is to maximize the value for its shareholders. In this view, which is also referred to as Friedman's doctrine, it is believed that society at large benefits most if companies simply focus on maximizing their own profits. Consequently, any corporate social responsibility (CSR) initiative is obsolete. Stakeholder theory, first proposed by Freeman (1984), takes a different view on the role of a business. The responsibility of a firm should not be limited to the shareholders, but should consider all the stakeholders. This is not only believed to increase overall welfare, but also the profitability of individual firms as the theory argues that a good relationship with all the stakeholders will improve long-term financial performance. Following these 
two seminal papers, many other scholars have published on the topic in the field of strategic management. McWilliams and Siegel (1997) and Jensen (2002) confirm the CSR skepticism of Friedman (1970). Porter and van der Linde (1995) find that sustainable firm policies can lead to a competitive advantage, which is in concordance with Freeman's (1984) idea that a firm's social responsibility not only encompasses its shareholders. Reconciliating the opposing views, Mackey, Mackey and Barney (2007) find that demand and supply conditions for socially responsible investment opportunities determine whether socially responsible decisions can lead to better financial performance.

The same debate on the financial performance of SRI funds has been going on in the field of financial economics. Mostly, researchers have implemented empirical models to compare the financial performance of SRI and conventional funds, controlling for different factors of risk. The first empirical studies go back to Moskowitz (1972) and Bragdon and Marlin (1972), who find a positive rank correlation between corporate social and financial performance. The sophistication of the applied methods has since then increased, and so has the quality of results. Following the rank correlation tests, SRI performance was researched using the capital asset pricing model (CAPM; Sharpe, 1964), controlling only for market risk (e.g. Hamilton, Jo, \& Statman, 1993), and using performance ratios like the Sharpe index (e.g. Sauer, 1997). As more recent advances in empirical asset pricing got adopted across the field, the CAPM was gradually replaced by the Fama-French (1993) three-factor model and the Carhart (1997) four-factor model (e.g. Bauer, Koedijk, \& Otten, 2005). Today, most SRI performance research implements a conditional four-factor model, following Ferson and Schadt (1996), taking into account possible time-varying risk. A full conditional model, following Christopherson (1998), takes into account time-varying alphas as well. However, results from the full conditional model have rejected the hypotheses of alphas varying in time (e.g. Cortez, Silva, \& Areal, 2009). Given these different possible approaches, Geczy, Stambaugh, and Levin (2003) found that the cost of investing in SRI funds instead of conventional funds crucially depends on two elements: the belief held by the investor regarding the valid underlying asset pricing model, and the ability of fund managers to select stocks. The cost of investing in SRI when assuming the CAPM holds true and fund managers have no stock-picking skills is negligible. However, the cost is substantial when adhering to a four-factor model and assuming that fund managers have some skills in selecting stocks.

Regardless of the evolution in the methodological approach of researching the performance of SRI funds, contradictory results have been found from the start. This led scholars to divide into believers and nonbelievers of SRI, each with their own set of arguments. The non-believers, who argue that SRI funds can only underperform traditional funds, mainly refer to modern portfolio theory (Markowitz, 1952). Because social screening adds constraints to the optimization problem of finding an efficient portfolio, some idiosyncratic risk cannot be diversified away. Consequently, SRI portfolios are not on the efficient frontier and thus will yield subpar risk-adjusted returns. The critique of the non-believers is also in line with the argument of Friedman (1970). Engaging in socially responsible activities increases the operational costs of a firm, which negatively impacts overall profitability. The believers contend that social responsibility is not a cost, but rather an investment as firms are an inherent part of their social environment (Granovetter, 1985). This view is supported by stakeholder theory (Freeman, 1984). Additionally, the believers refute the argument that social screening leads to inefficient portfolios. Even though the pool of potential stocks to diversify away idiosyncratic risk is smaller because of the additional constraints, the quality of this pool is believed to be higher as the screening process yields value-relevant information for the investor (Barnett \& Salomon, 2006).

\section{Challenges and issues for SRI}

Despite the progress of SRI as an asset class, the SRI performance debate yet needs to be settled. From this debate, and from several other developments, we identify four important challenges for the continued growth of SRI, both in the academic and the professional world.

A first challenge concerns the methodological approach for the performance analysis of SRI funds in academics. From the review of methodologies to test for SRI performance, we learn that measuring risk-adjusted returns from asset pricing models is standard practice today. To compare SRI and conventional funds, a difference portfolio is usually constructed from a dichotomous dummy variable that indicates whether the fund 
is labeled socially responsible or not. The problem with the dummy approach is that it neglects possible heterogeneity among different SRI funds and that it does not take into account the multiple dimensions relevant to social responsibility. In reality socially responsible investors do not adopt a dichotomous classification approach and need to carefully examine the mutual funds' prospectus to examine if the fund's investment strategy and social responsible guidelines meet their individual ethical standards (Hollingworth, 1998). Hoggett and Nahan (2002) and Tippet (2001) show that this kind of SRI investment information might be hard to retrieve or even be unreliable. Barnett and Salomon (2006) already addressed the issue of dichotomy and found a curvilinear relationship between corporate social and financial performance. These findings even suggest that both sides of the debate on SRI performance could coexist peacefully. Schwartz (2003) and Koellner, Weber, Fenchel and Scholz (2005) propose a general code of ethics for socially responsible investing regarding the information disclosure or transparency, the investment process and the credibility of information, but there is a lack of specific social responsible indicators that capture the multifaceted nature of SRI. A methodology to overcome the dichotomous measurement of social responsibility in asset pricing models is still lacking. We believe that the development of a social responsibility indicator to score and/or classify funds based on multiple criteria decision analysis (MCDA) methodologies could overcome this issue. The MCDA field is devoted to the development of appropriate methodologies that can be used to support and aid decision makers in circumstances where multiple conflicting decision factors (objectives, goals, criteria) have to be considered simultaneously. The application of MCDA to finance problems is not new (see e.g. Steuer \& Na (2003) and Zopounidis \& Doumpos (2002) for an overview of this line of research). In the next section, we present a non-technical overview of MCDA methodologies, and a concrete approach for building a social responsibility indicator from these methodologies.

The lack of a proper regulatory framework in the certification of mutual funds is the second challenge. Although at the company level, several independent agencies ${ }^{1}$ try to supply transparent and credible information about the social, labor and environmental performance of corporations throughout the world, few rating agencies monitor the social responsibility value/authenticity of mutual funds. Most of these agencies only provide financial information about the funds (costs, performance, risk and liquidity) and conventional investment strategy information (type of security, country and industry allocation, financial investment objectives and fund composition). Supervising authorities are currently unable to adequately screen the ethical value of mutual funds to, for example, grant a certificate of "ethical authenticity" to funds or to promote ethical investments all together. As SRI is becoming more popular, this gives an incentive to investment institutions to label their mutual funds socially responsible, even though this is not really the case. The MCDA framework can again help to create a tool to classify mutual funds based on an assessment of a wide variety of underlying socially responsible criteria.

In the absence of a clear framework to define and categorize SRI funds, commercial banks need to spend time and resources to develop, implement and communicate an in-house SRI view. This forms the third challenge to the further development of SRI. A framework based on MCDA can help companies to construct SRI mutual funds in a more efficient, consistent and transparent way. Consequently, consumers would be less confused by standalone SRI definitions that differ from bank to bank and would be enabled to compare the ethical value of different mutual funds in a straightforward manner. Assessing an investment alternative would then be possible along three dimensions: risk, return and social responsibility. Such a framework would also help supervising authorities to adequately screen the social content of mutual funds in granting "SRI certificates".

These first three challenges are rather similar, in the sense that they can be addressed in the same way. They all need an overarching framework that can help in scoring and classifying mutual funds based on social responsibility. More specifically, a social performance indicator can be helpful in discriminating between the social responsibility content of mutual funds in a more continuous way, it would give regulators a tool to develop labels - based on categories or scores - for genuine SRI funds and it would facilitate the process of developing new SRI mutual funds for banks. This performance indicator needs to be as general as possible, taking into account views from all the different stakeholders and interest groups involved in the SRI debate.

\footnotetext{
${ }^{1}$ Some examples are KLD, Ethibel, Vigeo, Innovest, Oekom Research, SAM, Jantzi Research, Corporate Monitoring, EthicScan Canada and EIRIS.
} 
A more concrete approach for developing this indicator is presented in section 4.

A final outstanding challenge for the field of SRI was revealed by the 2012 Eurosif report on the European SRI mutual fund industry. Even though the SRI market continues to grow, the retail segment remains underdeveloped as growth and volume in the SRI market predominantly comes from institutional investors. For the overall European mutual fund industry, 25\% of assets under management are held by retail investors (European Fund and Asset Management Association, 2013). Retail investments in the European SRI mutual fund industry only amount to $6 \%$ of assets under management, which is illustrative of a large potential for growth (Eurosif, 2012). As a main reason for this underdevelopment of the European SRI retail mutual fund market, Eurosif (2012) points towards bad communication and a lack of transparency and clarification of SRI strategies, which keeps many retail investors from investing in SRI funds. Again, MCDA could provide the framework to overcome this challenge, as the methodology can assist retail investors in handling extensive information in a transparent way. As MCDA is focused on accommodating better decisions, it can also assist retail investors in making wiser investment choices. Similar to the investment services directive by the European Commission to allow investors to better understand the risk they want to take, we believe the MCDA framework could be formalized into a "green" MiFID (Markets in Financial Instruments Directive) questionnaire, which could assist investors in better understanding their social responsibility preferences and increase the investor protection in Europe with respect to SRI (Davies, Dufour, \& Scott-Quinn, 2006). Note that the MCDA tool to address this challenge needs to be more tailored to the needs of individual investors, which sets the fourth challenge apart from the first three.

Clearly, MCDA could be instrumental in addressing all of the above challenges. This is not to say that MCDA is the magic formula that will resolve each and every issue, but merely that it can provide the framework to help move the SRI field to the next level. In order to further explore and guide future research, we review the different schools of MCDA methodologies and show how these methods could be used as a tool to define and evaluate SRI funds.

\section{MCDA as a tool to define and evaluate SRI}

\subsection{Introduction to MCDA}

The development of MCDA, an advanced field of operations research, is based on the simple finding that a single objective, goal, criterion or point of view is rarely used to make real-world decisions. The MCDA field is devoted to the development of appropriate methodologies that can be used to support and aid decision makers in situations where multiple conflicting decision factors (objectives, goals, criteria) have to be considered simultaneously. Given the different dimensions to the concept of social responsibility, MCDA is also relevant in scoring and classifying SRI mutual funds.

Within a multi-criteria context, decision-making problems are realized in the following paradigm: a decision maker considers a set of alternatives and seeks to take an "optimal" decision considering all the factors that are relevant to the analysis. Since these factors usually lead to conflicting results and conclusions, the "optimal" decision is not really optimal in the traditional optimization perspective. Instead, it is a satisfactory non-dominated decision, i.e. a decision that is in accordance with the decision makers system of values and is not dominated by other possible decisions.

Decisions made within this context may be expressed in different forms, which are referred to as "problematics" (Roy, 1996): problematic $\alpha$ : choosing one alternative; problematic $\beta$ : sorting the alternatives in homogenous groups defined in a preference order; problematic $\gamma$ : ranking the alternatives from best to worst; problematic $\delta$ : describing the alternatives in terms of their performance on the criteria. The selection of an investment project is a typical example of a financial decision-making problem where problematic $\alpha$ (choice) is applicable. The classification of mutual funds according to their social performance is an example of problematic $\beta$, the comparative evaluation and ranking of stocks according to their financial and stock market performance is an example of problematic $\gamma$, whereas the description of the financial characteristics of a set of firms is a good example of problematic $\delta$. 
In the discrete case, the set of decision alternatives (A) is assumed to include a finite number of clearly identifiable alternatives. This situation is often met in several financial decisions, such as bankruptcy prediction and credit risk assessment (A: a set of firms), portfolio selection (A: a set of stocks/funds), venture capital investments (A: a set of venture capital financing proposals), country risk evaluation (A: a set of countries). Irrespective of whether the set of alternatives A is discrete or continuous, making a decision in a multi-criteria context requires the appropriate aggregation of all the pertinent decision factors, which are referred to as "evaluation criteria" or simply "criteria". Formally, a criterion is a non-decreasing real-valued function that describes an aspect of the global performance of the alternatives and defines how the alternatives are compared to each other.

In making a decision within this multi-criteria context the aggregation of the criteria is a crucial process. This aggregation can be performed in many different ways depending on the form of the criteria aggregation model. Within the MCDA field one can distinguish three main forms of aggregation models: outranking relations (relational form), utility functions (functional form) and decision rules (symbolic form). The construction of an aggregation model is mainly of interest in the case where A is discrete. In such a case the alternatives are clearly identifiable and consequently their performance on each criterion can be specified, rather easily. In the case where $\mathrm{A}$ is continuous, however, this is not a straightforward process, simply because it is impossible to identify all the alternatives that are relevant to the analysis. In this case special interactive aggregation techniques have been developed in MCDA to allow the efficient search of the solution space.

In all cases, the aggregation of the criteria is performed so as to respect the decision makers (DM)'s judgment policy. To ensure that this objective is achieved some information on the preferential system of the DM must be specified, such as the criteria weights. The required preferential information can be specified either through direct procedures in which a decision analyst elicits it directly from the DM, or through indirect procedures in which the DM provides examples of the decision situations that he faces and the decision analyst analyses them to determine the required preferential parameters which are most consistent with the DM's global evaluations. The latter approach is known in the MCDA field as "preference disaggregation analysis" (Jacquet-Lagrèze \& Siskos, 1982, 1983, 2001).

It is recognized that the MCDA models can be classified into three broad categories, or schools of thought, namely: (1) value measurement models in which one decision option may be preferred to another and for which scores are developed initially for each individual criterion, and then synthesized in order to effect aggregation into higher level preference models; (2) outranking models in which alternative courses of action are compared pairwise, initially in terms of each criterion, in order to identify the extent to which a preference for one over the other can be asserted. In aggregating such preference information across all relevant criteria, the model seeks to establish the strength of evidence favoring selection of one alternative over the other; (3) goal, aspiration or reference level models in which desirable or satisfactory levels of achievement are established for each of the criteria. The process then seeks to discover options, which are in some sense closest to achieving these desirable goals or aspirations. This approach is particularly useful in the case where A is continuous.

A number of authors have highlighted the similarities of data envelopment analysis (DEA) and MCDA models, commenting principally from a theoretical perspective on the mathematical structure and methods for solution. Given these similarities it is possible that the two approaches could be viewed as competing. DEA could be described as an approach, which seeks to extract as much as possible from "objective" historical data, without resort to subjectivity. In contrast, MCDA actively seeks to elicit, understand and manage value judgments. It has been suggested that DEA is an appropriate tool for monitoring and control, whereas MCDA is most appropriate in the context of evaluation and choice. However, there are many applications, which cross these boundaries. Belton and Stewart (1999) suggest that there are many ways in which the two approaches can be used complementary and that each can learn important lessons from the other.

We now introduce the different schools of MCDA methods in more detail, after which we look at the way these methods could be applied to address the issues presented in section 3 . 


\subsection{Value measurment methods}

\section{Multi-attribute value theory}

The idea behind value measurement methods is to formulate a quantitative score for every alternative based on an aggregate value judgment of the relevant criteria (see e.g. Belton \& Stewart, 2002). This score could then be used to rank or classify alternatives. The most straightforward approach is to score each alternative on every individual criterion, and then calculate a weighted sum of these partial scores based on the DM's judgment of the relevant importance of each criterion.

Multi-attribute value theory (MAVT) is an extension of basic value measurement methods that takes into account possible non-linearity of the preference functions. In a first step, a hierarchical value tree, which represents the hierarchy of relevant criteria in scoring different alternatives, has to be constructed. In constructing the value tree, it is important to consider the condition of preferential independence, which means that tradeoffs between different criteria should not depend on any other criteria. Once the alternatives have been determined, the second step consists of constructing a performance table by scoring the different alternatives with respect to the different criteria. If the decision maker feels comfortable with the alternatives and the criteria, the scoring process can be completed by direct assessment. If the decision maker has more difficulties with the scoring process, other scoring methods can be considered: e.g. indirect assessment, using qualitative scales or by pairwise comparison.

The distinctive feature of MAVT is in the elicitation of partial value functions for each criterion, which represent the utility derived by the DM from the performance of an alternative with respect to a single criterion. Deriving the true underlying value function is not straightforward. To help the DM in this complex process, value functions can be derived in an indirect way, for example, via standard differences or via bisection methods. In the former case, the DM is first asked to define improvements in the scores of the different criteria as a comparison standard, very much like a ruler for measuring distances. Starting from an initial score for a certain criterion, the DM is then asked to provide a new score for which the increase is comparable to the comparison standard that was defined before. From this new value, the same step is repeated. From the DM's judgments of these simpler questions, the value function can be elicited. Another way is to elicit preferences using the bisection method. In this case, the DM is asked to define scores for each criterion that correspond to the minimum (0) and maximum (1) level of satisfaction. Next, the DM provides the score that would be in the middle of the minimum and maximum score. In later iterations, the interval is bisected even more to derive more detailed value functions.

Next to determining the underlying partial value functions, weights of criteria need to be elicited. Again, different methodologies can be applied. Either the DM feels comfortable assessing the importance of criteria directly, or methods like preference disaggregation analysis are used (Jacquet-Lagrèze \& Siskos, 1982, 1983, 2001). In a final step, the overall score for each alternative is calculated aggregating the partial value functions on the basis of the elicited weights for every criterion. Different forms of aggregation are possible (e.g. additive or multiplicative). Note that this final step is not the same as a simple weighted sum, since only the transformed utility values from the partial value functions are used for each criterion, and not the direct scores from the performance table itself. Different software packages are available to implement the MAVT technique (e.g. D-Sight, diviz).

Similar to MAVT is multi-attribute utility theory (MAUT), which is based on expected utility theory and calls for even stronger assumptions. The main advantage of MAUT is the possibility to take into account uncertainty and risk. However, this makes it even more complex to elicit final scores for the alternatives. Therefore, MAVT is still the preferred methodology in approaching real-life decision problems. For a more complete overview of these techniques, see for example Keeny and Raiffa (1993).

\section{Analytic hierarchy process}

The analytic hierarchy process (AHP), presented in detail by Saaty (1980), is an elegant approach in its simplicity, for addressing and analyzing discrete alternative problems with multiple conflicting criteria. 
Like MAVT, the AHP starts by subdividing a problem into a hierarchy of overall objective criteria. As we work to build this AHP hierarchy, we increase our understanding of the problem as a whole. Particular about AHP is the use of pairwise comparisons to elicit the criteria weights from experts. Psychologists argue that it is easier and more accurate to express one's opinion on only two alternatives than simultaneously on all the alternatives. It also allows consistency cross checking between the different pairwise comparisons. Starting at the bottom level of the hierarchy, we conduct pairwise comparisons between the elements immediately below each other element. Under real conditions, it is not difficult, based on the condition of transitivity, to identify improperly filled in questionnaires. The AHP method assesses the consistency of each expert's opinions and defines a consistency index (Saaty, 1980, 2005).

One of AHP's strengths is the possibility to evaluate quantitative as well as qualitative criteria and alternatives on the same preference scale. These can be numerical, verbal or graphical. The use of verbal responses is intuitively appealing, user-friendly and more common in our everyday lives than numbers. Nevertheless, it may also allow some ambiguity in non-trivial comparisons, which has been criticized (Donegan, Dodd, \& McMaster, 1992). Because of using pairwise comparisons AHP uses ratio scales, which requires an absolute zero. Barzilai (2005) claims that preferences cannot be represented with ratio scales, because in his opinion an absolute zero does not exist, as with temperature or electrical tension. Saaty (1994) states that ratio scales are the only possible measurement if we want to be able to aggregate measurement, as in a weighted sum. Dodd \& Donegan (1995) also criticized the absence of a zero in the preference scale.

To derive priorities, the verbal comparisons must be converted into numerical ones. In Saaty's AHP the verbal statements are converted into integers from one to nine. Theoretically there is no reason to be restricted to these numbers and verbal gradation. Although the verbal gradation has been little investigated, several other numerical scales have been proposed. Harker and Vargas (1987) have evaluated a quadratic and a root square scale in only one simple example and argued in favor of Saaty's 1-9 scale. However, one example seems not enough to conclude the superiority of the 1-9 linear scale. Lootsma (1989) argued that the geometric scale is preferable to the 1-9 linear scale. Salo and Hamalainen (1997) point out that the integers from one to nine yield local weights, which are unevenly dispersed, so that there is lack of sensitivity when comparing elements, which are preferentially close to each other. Based on this observation, they propose a balanced scale where the local weights are evenly dispersed over the weight range $(0.1,0.9)$. Earlier Ma and Zheng (1991) have calculated a scale where the inverse elements $\mathrm{x}$ of the scale $1 / \mathrm{x}$ are linear instead of the $\mathrm{x}$ in the Saaty scale. Donegan et al. (1992) have proposed an asymptotic scale avoiding the boundary problem. Ji and Jiang (2003) propose a mixture of a verbal and a geometric scale. The possibility to integrate negative values in the scale has also been explored (Millet \& Schoner, 2005; Saaty \& Ozdemir, 2003). Among all the proposed scales, the linear scale with the integers one to nine and their reciprocals has been used by far the most often in applications. Saaty $(1980,1991)$ advocates it as the best scale to represent weight ratios. However, the cited examples deal with objective measurable alternatives such as the areas of figures, whereas AHP mainly treats decision processes as subjective issues. Salo and Hamalainen (1997) demonstrate the superiority of the balanced scale when comparing two elements. Clearly, the choice of the "best" scale is a very heated debate. Some scientists therefore argue that the choice of scale depends on the person and the decision problem (Harker \& Vargas, 1987; Pöyhönen, Hamalainen, \& Salo, 1997).

Enforcing consistency is another important contribution of the AHP. By itself, a questionnaire cannot identify inconsistencies. According to Saaty (1994): "the AHP can show one by one, in sequential order, which judgments are the most inconsistent, and also suggests the value that best improves consistency." By providing the expert an opportunity to re-examine preferences in a guided format, the AHP enables a better understanding of the importance of the criteria. Saaty (1980) suggested that a consistency ratio value of $10 \%$ or less is considered acceptable. Otherwise, it is recommended that the DM revises the weight assignment to resolve inconsistencies in the pairwise comparisons.

AHP still suffers from some theoretical disputes. Rank reversal is surely the most debated problem. This phenomenon is still not fully resolved and may never be because the aggregation of preferences transposed from scales of different units is not easily interpretable and even questionable according to Roy (1996). In 
this sense, the rank reversal problem is not specific to AHP, but to the normalization of scores. The assumption of preferential independence may also be a limitation of AHP (and other MCDA methods). The analytic network process (ANP), a generalization of AHP with feedbacks to adjust weights, may be a solution. However the decision maker must answer a much larger number of questions, which may be complex (Saaty \& Takizawa, 1986). A simplified ANP, while still keeping its proprieties, would be beneficial for a wider adoption of the method (Ishizaka \& Labib, 2011). The choice of a hierarchy and a judgment scale is also important and difficult. Problem structuring methods could help in the construction of AHP hierarchies, which is its less formalized aspect (Petkov \& Mihova-Petkova, 1997; Petkov, Petkova, Andrew, \& Nepal, 2007).

Several works can be found in the literature relating AHP with finance. Beyond improving the quality of the decisions, the AHP is shown as a useful tool to support the process of examining, justifying, negotiating, and communicating ethical decisions (Pérez-Gladish \& M'Zali, 2010). For all the above reasons, and taking into account the existence of criticisms to the technique, AHP seems a valuable candidate for the ranking of mutual funds based on several socially responsible criteria, although other MCDA techniques could also be applied to the resolution of this problem.

\section{Other value measurement methods}

Other value measurement models are MACBETH (Measuring Attractiveness by a Categorical Based Evaluation TecHnique; Bana e Costa \& Vansnick, 1994), the dissagrigation methods UTA (UTilités Additives; Jacquet-Lagrèze \& Siskos, 1982) and UTADIS (UTilités Additives DIScriminantes; Jacquet-Lagrèze \& Siskos, 1982; Zopounidis \& Doumpos, 1999).

\subsection{Outranking methods}

\section{ELimination Et Choix Traduisant la REalité (ELECTRE)}

The ELECTRE family of methods by Roy (1985) is based on the concept of outranking:"one solution outranks another if it is at least as good as the other in most respects, and not too much worse in any one respect. For instance, Martel, Khoury and Bergeron (1988) employ ELECTRE to study the limitations of conventional risk in being able to capture global risk in a portfolio context. Also influenced by ELECTRE is BANK ADVISER by Mareschal and Brans (1991), which has been successful in the banking industry. Members of the ELECTRE family are ELECTRE I, II, III, IS, IV and TRI.

\section{Preference Ranking Organization METHod for Enrichment Evaluations (PROMETHEE)}

Originally developed by Brans and Vincke (1985), PROMETHEE is also based on the theory of outranking relations. The outranking methods include two phases: the construction of an outranking relation, and the exploitation of this relation in order to assist the decision-maker. The basic principles of the PROMETHEE method in relation with other methods of the same field are the following: extension of the notion of criteria, valued outranking relation and exploitation of the outranking relation. In the PROMETHEE method the valued outranking relation is less sensitive to small modifications and its interpretation is straightforward. The exploitation of the valued outranking relation of the PROMETHEE method refers to the case in which the alternatives have to be ranked from best to worst. Brans, Vincke and Mareschal (1986) use six types of functions that cover most of the cases occurring in practical applications. The PROMETHEE analysis may be used in conjunction with a procedure termed GAIA (Geometric Analysis for Interactive Aid), which provides a two-dimensional graphical representation of the multi-dimensional problem (Brans \& Mareschal, 1990). Members of the PROMETHEE family are PROMETHEE I, II, III, IV, V and GDSS.

\subsection{Goal, aspiration, or level reference methods}

The advantage of goal programming (GP) is that multiple criteria can be incorporated into a model that can be solved using conventional (single criterion) optimization software. GP's disadvantage is that information about the decision maker's preferences is required a priori in the form of priority levels, importance weights, and goal target values. The goal programming models can be divided into linear goal programming models, interactive multiple goal programming (IMGP) and interactive sequential goal programming (ISGP). 
These kinds of models are especially useful when the set of alternatives is continuous. For example, goal programming might come in handy when determining the optimal funds-of-funds strategy or when managing a portfolio of socially responsible investments (e.g. Hallerbach, Ning, Soppe, \& Spronk, 2004).

\subsection{Application of MCDA framework to SRI issues}

All of the challenges presented in section 3 can be addressed using MCDA methodologies. As pointed out before, the first three challenges are similar in the sense that they can be addressed by an social responsibility indicator to score and classify mutual funds with respect to social performance. The fourth challenge, which considers the untapped potential of the retail side of the SRI market, requires an MCDA framework that can be tailored to the needs of individual clients to better understand the SRI concept and their social investment preferences.

\section{Social performance indicator}

Using the MCDA framework, a social performance indicator for mutual funds can be built. Instead of using a dichotomous classification, an indicator would make it possible to discriminate between mutual funds on the basis of their social performance in a more continuous way. This can be achieved either by calculating a raw social performance score, or by allocating mutual funds to different categories based on their social performance. Both options can be achieved using MCDA methods. Having a social performance indicator would allow scholars to have a better look at the corporate social versus corporate financial performance relationship. Regulators could use the indicator to grant sustainability certificates to the mutual funds best performing with respect to ESG criteria. Banks can be assisted by such an indicator to improve their line of SRI products. Overall, the indicator would increase the transparency and clarity of the supply of SRI products.

In developing the indicator, it is necessary to first define a relevant and consistent set of criteria for assessing the social responsibility content of a mutual fund, taking into account views from different stakeholders. This set of criteria needs to be comprehensive and yet as compact as possible. The assumption of preferential independence also needs to be fulfilled. A useful tool to define the set of criteria is the value-focused thinking approach by Keeney (1992), which structures the process of defining relevant criteria. The definition of a valid set of criteria requires the collaboration of an expert panel representing the different stakeholders involved with the SRI decision process. To help find the relevant groups of stakeholders, Checkland's CATWOE model might be used (Checkland \& Scholes, 1990). In applying the AHP to score mutual funds on social performance, Perez-Gladish and M'Zali (2010) already developed a set of criteria. However, they only used one expert to establish the list of criteria, so future research needs to consult representatives from all different interest groups to ensure that the set of criteria is comprehensive and consistent with the different views from the field of SRI.

Once the consistent set of criteria is found, the alternatives need to be considered. This set of alternatives will depend on the application of the social performance indicator. For academic purposes, a scholar might have a good reason to consider only a small subset of mutual funds. For the purpose of government regulation, the set of alternatives might include all the mutual funds from a certain country or region. In applying the social performance indicator in the banking industry, the set of alternatives might consist of different potential mutual funds that the bank wants to release in the near future. Given that the set of alternatives can be different for the different parties, it is of keen importance to build the social performance indicator in such a way that it is independent from the underlying set of alternatives.

The next step is to choose a particular MCDA model to build the social performance indicator. From the school of value measurement methods, different methodologies can be applied to the problem at hand. AHP has been successfully implemented in the past, although given a limited number of experts determining the set of criteria. MAVT can also be applied, as it is a more general form of the AHP, on the condition that enough information can be collected from the expert panel about the form of the partial utility functions. Another value measurement method that is feasible for this problem is MACBETH, which is similar to AHP but uses categorical instead of ratio scales. In the outranking school of MCDA methods, both PROMETHEE, 
together with its visual aid GAIA, and ELECTRE can be used as a tool to classify mutual funds based on outranking relations. The third class of models - goal programming methods - is less applicable as a social performance indicator, as it requires an association of every criterion with quantitative and measurable attributes, which is not the case with some of the softer criteria related to SRI. However, the goal programming methods can be used either ex-ante to narrow down a broad set of alternatives, or ex-post to find the optimal way of implementing a fund-of-funds strategy. For all of these methodologies, it is important to consider underlying assumptions (e.g. rank reversal, preferential independence).

To implement these different methodologies, and to find the most robust and qualitative one to score mutual funds on their social performance, a lot of information is needed as an input. This information should be collected from the expert panel of representative stakeholders. Therefore, a key success factor is to collect this information in the most efficient way possible, as it seems unlikely that such an expert panel can be consulted regularly. We suggest that a questionnaire, consisting of all the relevant questions to implement the different methodologies, is constructed. This will not be straightforward, as the different methods require quite different sets of information.

Once the criteria have been defined, a sample set of alternatives is constructed and all the necessary information is collected, different methods can be implemented to build the social performance indicator. Instead of choosing only one of the methods ex-ante, we suggest that future research has a look at every feasible model that can be applied to the problem. After the models are built, robustness and sensitivity analyses on these different models can help to determine which model is most qualitative and robust in judging the social performance of a mutual fund. These robustness checks can either be executed using built-in software modules that alter input values and consider the changes in output, or using more statistical procedures like Gini's concept of transvariation (e.g. Van den Bossche, Rogge, Devooght, \& Van Puyenbroeck, 2010). Furthermore, feedback from the expert panel can be used to determine what kind of model is most in line with the expertise from different stakeholders in the field of SRI. Finally, the best performing model can be used as a social performance indicator to score and/or classify mutual funds with respect to social performance. This indicator can then be applied to address the academic, regulation and commercial bank challenges presented in section 3 .

\section{"Green" MiFID}

To address the underdeveloped state of the retail end of the SRI mutual fund market, the MCDA framework could also be adopted by banks to help their customers better understand the variety of SRI mutual funds being offered. The main difference with the social performance indicator is that this tool needs to be tailored to the individual needs of investors. Instead of looking for a consensus on the set of criteria and their importance from an expert panel of representative stakeholders, individuals now need to provide input that represents their preferences. Ideally, the best performing model found when constructing the social performance indicator could be used on the individual level as well, just by replacing input from the expert panel by individual information provided by investors. However, chances are that this approach would be too technical for a straightforward implementation in standard investment advisory practice. Therefore, we suggest that future research explores to what extent it is possible to transform the principles behind the best possible MCDA methodology into a standardized questionnaire that would be better suited to help clients in getting to know SRI products and their preferences towards these products in a better way. As an interesting example, we point to the European Commissions' directive called MiFID, which obliges banks to let their investors complete a questionnaire to get to know their personal investment profile. As a result, a client interested in investing is sorted into a certain category, which comes with certain rules of protection (Davies, Dufour, \& Scott-Quinn, 2006). The directive provides transparency and tries to protect retail investors from investing in products that are incompatible with their preferences. In a similar way, we propose a so-called "green" MiFID to be called into life. Retail investors interested in SRI would need to complete a survey, the questions of which are based on the underlying MCDA framework, to get more insight into their preferences with regard to social investing.

It is worth noting that this "green" MiFID is compatible with the social performance indicator in opening 
up the retail side of the SRI market. The social performance indicator at the supply side of the SRI market increases product transparency as it accommodates the comparison of different mutual funds with respect to their performance on ESG criteria. The "green" MiFID provides retail investors a better insight into their personal SRI profile. Together, these two measures make it possible for individual investors interested in SRI to get a clear insight into what products are best suited to match their preferences, which exactly addresses the main cause of the SRI retail market remaining underdeveloped.

\section{Conclusion}

The practice of socially responsible investing (SRI) goes back a long way. Being a niche investment philosophy at first, SRI has now matured and can no longer be disregarded by the investment community. Nevertheless, the debate on the out- or underperformance of SRI mutual funds with respect to conventional funds is still raging. Advocates of SRI point to the value of social screening; the non-believers adhere to modern portfolio theory that states that additional constraints on the investment universe cannot possibly increase portfolio efficiency. Next to this debate remaining unsettled, we highlight four challenges that are facing SRI and a framework that could be used in future research to address these.

A first group of challenges revolves around the need for a social performance indicator that is able to score and/or classify mutual funds on basis of their social responsibility. Such an indicator could enable scholars to better examine the relative performance of SRI mutual funds; it can help the regulatory authorities in developing a certificate for genuinely socially responsible mutual funds; and it accommodates the process for banks to develop new and transparent SRI mutual funds. Another challenge concerns the underdevelopment of the retail side of the SRI market. To tap the potential at this side of the market, there is the need for a tool that can help investors to better understand the SRI products and their own preferences with respect to these products.

Given these two groups of challenges, we point to multi-criteria decision analysis (MCDA) as the methodological framework that could be used in future research to develop appropriate solutions. Different MCDA methodologies can be implemented to build a social performance indicator that would address the first group of challenges. Using robustness analyses and feedback from an expert panel representing the main stakeholders in the SRI debate, it should be possible to determine the best possible MCDA method to score and classify mutual funds on the basis of their social performance. This would benefit academic research, the regulatory burden of governments and the efforts of banks to create new SRI products. From this MCDA indicator, it should also be possible to create a simple tool based on a standard questionnaire that can help investors to better understand their own preferences with regard to the social responsibility of financial products. Such a tool is comparable to the current MiFID tool that is used in banks to help clients understand their risk preferences when investing in financial products.

Note that the indicator on the one hand, and the "green" MiFID tool on the other hand, are not unrelated. Ideally, they should be aligned as to stimulate the further growth of the SRI market. The indicator, among other things, can create more transparency in the supply of SRI financial products and makes it easier to discriminate between mutual funds on the basis of their social performance (using scores or classes). The investor tool can help learn potential investors about their social performance preferences (using MiFID classes). Together, these two tools have the potential to open up new perspectives for the retail side of the SRI market, which could further add to the growth of the SRI investment universe.

\section{References}

Bana e Costa, C. and Vansnick, J. (1994). MACBETH - An interactive path towards the construction of cardinal value functions. International Transactions in Operational Research, 1(1):107-114.

Barnett, M. L. and Salomon, R. M. (2006). Beyond dichotomy: The curvlinear relationship between social responsibility and financial performance. Strategic Management Journal, 27(11):1101-1122. 
Barzilai, J. (2005). Measurement and prefence function modeling. International Transactions in Operational Research, 12(2):173-183.

Bauer, R., Koedijk, K., and Otten, R. (2005). International evidence on ethical mutual fund performance and investment style. Journal of Banking \&3 Finance, 29(7):1751-1767.

Belton, V. and Stewart, T. J. (2002). Multiple criteria decision analysis: An integrated approach. Kluwer Academic Publishers, Boston.

Bragdon, J. and Marlin, J. (1972). Is pollution profitable? Risk Management, 19(4):9-18.

Brans, J. and Mareschal, B. (1990). The PROMETHEE methods for MCDM; the PROMCALC, GAIA and BANK ADVISER software. In Bana e Costa, C., editor, Readings in multiple criteria decision aid, pages 216-252. Springer Verlag, Berlin.

Brans, J. and Vincke, P. (1985). A preference ranking organisation method: The PROMETHEE method for multiple criteria decision-making. Management Science, 31(6):647-656.

Brans, J., Vincke, P., and Mareschal, B. (1986). How to rank and how to select projects: The PROMETHEE method. European Journal of Operational Research, 24(2):228-238.

Carhart, M. (1997). On persistence in mutual fund performance. Journal of Finance, 52(1):57-82.

Checkland, P. and Scholes, J. (1990). Soft systems methodology in action. John Wiley \& Sons, Chichester.

Christopherson, J., Ferson, W. E., and Glassman, D. (1998). Conditioning manager alphas on economic information: Another look at the persistence of performance. Review of Financial Studies, 11(1):111-142.

Cortez, M. C., Silva, F., and Areal, N. (2009). The performance of European socially responsible funds. Journal of Business Ethics, 87(1):1-16.

Davies, R., Dufour, A., and Scott-Quinn, B. (2006). The MiFID: Competition in a new European equity market regulatory structure. In Ferrarini, G. and Wymeersch, E., editors, Investor protection in Europe: Corporate law making, the MiFID and beyond, chapter 6, pages 161-198. Oxford University Press, Oxford.

Dodd, F. and Donegan, H. (1995). Comparison of prioritization techniques using inter hierarchy mappings. Journal of the Operational Research Society, 46(4):492-498.

Donegan, H., Dodd, F., and McMaster, T. (1992). A new approach to AHP decision-making. The Statistician, $41(3): 295-302$.

European Fund and Asset Management Association (2013). Asset management in Europe: Facts and figures. Technical report, Brussels.

Eurosif (2012). European SRI Study. Technical report, Brussels.

Fama, E. F. and French, K. R. (1993). Common risk factors in the returns on stocks and bonds. Journal of Financial Economics, 33(1):3-56.

Ferson, W. E. and Schadt, R. W. (1996). Measuring fund strategy and performance in changing economic conditions. Journal of Finance, 51(2):425-461.

Freeman, R. (1984). Strategic management: A stakeholder approach. Pitman/Ballinger, Boston.

Friedman, M. (1970). The social responsibility of business is to increase its profits. New York Times Magazine, pages $32-33,122,124,126$.

Geczy, C. C., Stambaugh, R. F., and Levin, D. (2003). Investing in socially responsible mutual funds. University of Pennsylvania Working Paper.

Granovetter, M. (1985). Economic action and social structure: The problem of embeddedness. American Journal of Sociology, 91(3):481-510. 
Hallerbach, W., Ning, H., Soppe, A., and Spronk, J. (2004). A framework for managing a portfolio of socially responsible investments. European Journal of Operational Research, 153(2):517-529.

Hamilton, S., Jo, H., and Statman, M. (1993). Doing well while doing good? The investment performance of socially responsible mutual funds. Financial Analysts Journal, 49(6):62-66.

Harker, P. and Vargas, L. (1987). The theory of ratio scale estimation: Saaty's analytic hierarchy process. Management Science, 33(11):1383-1403.

Hoggett, J. and Nahan, M. (2002). Ethical investment - Deconstructing the myth. IPA Review, 54(3):3-6.

Hollingworth, S. (1998). Green investing: A growing concern? Australian CPA, 68(4):28-30.

Ishizaka, A. and Labib, A. (2011). Review of the main developments in the analytic hierarchy process. Expert Systems with Applications, 38(11):14336-14345.

Jacquet-Lagrèze, E. and Siskos, J. (1982). Assessing a set of additive utility functions for multicriteria decision-making, the UTA method. European Journal of Operational Research, 10(2):151-164.

Jacquet-Lagrèze, E. and Siskos, J. (1983). Methode de decision multicritere. Editions Hommes Et Techniques, Paris.

Jacquet-Lagrèze, E. and Siskos, J. (2001). Preference disaggregation : 20 years of MCDA experience. European Journal of Operational Research, 130(2):233-245.

Jensen, M. C. (2002). Value maximization, stakeholder theory, and the corporate objective function. Business Ethics Quarterly, 12(2):235-256.

Ji, P. and Jiang, R. (2003). Scale transitivity in the AHP. Journal of the Operational Research Society, 54(8):896-905.

Keeney, R. (1996). Value-focused thinking: A path to creative decisionmaking. Harvard University Press, Cambridge.

Keeney, R. and Raiffa, H. (1993). Decisions with multiple objectives: Preferences and value tradeoffs. Cambridge University Press, Cambridge.

Koellner, T., Weber, O., Fenchel, M., and Scholz, R. (2005). Principles for sustainability rating of investment funds. Business Strategy and the Environment, 14(1):54-70.

KPMG and ALFI (2013). European Responsible Investing Fund Survey 2013. Technical report, Luxembourg.

Lootsma, F. (1989). Conflict resolution via pairwise comparison of concessions. European Journal of Operational Research, 40(1):109-116.

Ma, D. and Zheng, X. (1991). 9/9-9/1 Scale method of AHP. In Second international symposium on AHP, pages 197-202, Pittsburgh.

Mackey, A., Mackey, T. B., and Barney, J. B. (2007). Corporate social responsibility and firm performance: Investor preferences and corporate strategies. Academy of Management Review, 32(3):817-835.

Mareschal, B. and Brans, J. (1991). BANK ADVISER: An industrial evaluation system. European Journal of Operational Research, 54(3):318-324.

Margolis, J. D. and Walsh, J. P. (2003). Misery loves companies: Rethinking social initiatives by business. Administrative Science Quarterly, 48(2):268-305.

Markowitz, H. (1952). Portfolio selection. Journal of Finance, 7(1):77-91.

Martel, J., Khoury, N. T., and Bergeron, M. (1988). An application of a multicriteria approach to portfolio comparisons. Journal of the Operational Research Society, 39(7):617-628. 
McWilliams, A. and Siegel, D. (1997). The role of money managers in assessing corporate social responsibility research. Journal of Investing, 6(4):98-107.

Millet, I. and Schoner, B. (2005). Incorporating negative values into the analytic hierarchy process. Computers and Operations Research, 32(12):3163-3173.

Moskowitz, M. (1972). Choosing socially responsible stocks. Business and Society Review, 1:71-75.

Orlitzky, M., Schmidt, F. L., and Rynes, S. L. (2003). Corporate social and financial performance : A meta-analysis. Organization Studies, 24(3):403-441.

Pérez-Gladish, B. and M'Zali, B. (2010). An AHP-based approach to mutual funds' social performance measurement. International Journal of Multicriteria Decision Making, 1(1):103.

Petkov, D. and Mihova-Petkova, O. (1997). The analytic hierarchy process and systems thinking. In 13th international MCDM conference, pages 243-252, Cape Town. Springer.

Petkov, D., Petkova, O., Andrew, T., and Nepal, T. (2007). Mixing multiple criteria decision making with soft systems thinking techniques for decision support in complex situations. Decision Support Systems, 43(4):1615-1629.

Porter, M. E. and van der Linde, C. (1995). Green and competitive: Ending the stalemate. Harvard Business Review, 73(5):120-134.

Pöyhönen, M., Hamalainen, R., and Salo, A. (1997). An experiment on the numerical modelling of verbal ratio statements. Journal of Multi-Criteria Decision Analysis, 6(1):1-10.

Renneboog, L., Ter Horst, J., and Zhang, C. (2008). Socially responsible investments: Institutional aspects, performance, and investor behavior. Journal of Banking \& Finance, 32(9):1723-1742.

Roy, B. (1985). Méthodologie multicritère d'aide à la décision. Economica, Paris.

Roy, B. (1996). Multicriteria methodology for decision analyis. Kluwer Academic Publishers, Dordrecht.

Saaty, T. (1980). Analytic hierarchy process. Decision Analysis, 50(1):579-606.

Saaty, T. (1991). Response to holder's comments on the analytic hierarchy process. Journal of the Operational Research Society, 42(10):909-929.

Saaty, T. (1994). Highlights and critical points in the theory and application of the analytic hierarchy process. European Journal of Operational Research, 74(3):426-447.

Saaty, T. (2005). The analytic hierarchy and analytic network processes for the measurement of intangible criteria and for decision-making. In Figueira, J., Greco, S., and Ehrgott, M., editors, Multiple criteria decision analysis: State of the art surveys, pages 345-408. Springer.

Saaty, T. and Ozdemir, M. (2003). Negative priorities in the analytic hierarchy process. Mathematical and Computer Modelling, 37(9-10):1063-1075.

Saaty, T. and Takizawa, M. (1986). Dependence and independence: From linear hierarchies to nonlinear networks. European Journal of Operational Research, 26(2):229-237.

Salo, A. and Hamalainen, R. (1997). On the measurement of preference in the analytic hierarchy process. Journal of Multi-Criteria Decision Analysis, 6(6):309-319.

Sauer, D. A. (1997). The impact of social-responsibility screens on investment performance: Evidence from the Domini 400 social index and Domini equity mutual fund. Review of Financial Economics, 6(2):137-149.

Schwartz, M. S. (2003). The "ethics" of ethical investing. Journal of Business Ethics, 43(3):195-213.

Sharpe, W. (1964). Capital asset prices: A theory of market equilibrium under conditions of risk. Journal of Finance, 19(3):425-442. 
Social Investment Forum (1999). Report on Socially Responsible Investing Trends in the United States. Technical report, Washington, D.C.

Sparkes, R. and Cowton, C. J. (2004). The maturing of socially responsible investment: A review of the developing link with corporate social responsibility. Journal of Business Ethics, 52(1):45-57.

Steuer, R. E. and Na, P. (2003). Multiple criteria decision making combined with finance: A categorized bibliographic study. European Journal of Operational Research, 150(3):496-515.

Telle, K. (2006). " It pays to be green" - A premature conclusion? Environmental and Resource Economics, $35(3): 195-220$.

The Forum for Sustainable and Responsible Investment (2012). Sustainable and responsible investing trends in the US. Technical report, Washington, D.C.

Tippet, J. (2001). Performance of Australia's ethical funds. Australian Economic Review, 34(2):170-178.

Van den Bossche, F., Rogge, N., Devooght, K., and Van Puyenbroeck, T. (2010). Robust corporate social responsibility investment screening. Ecological Economics, 69(5):1159-1169.

Zopounidis, C. and Doumpos, M. (1999). Business failure prediction using the UTADIS multicriteria analysis method. Journal of the Operational Research Society, 50(11):1138-1148.

Zopounidis, C. and Doumpos, M. (2002). Multi-criteria decision aid in financial decision making: Methodologies and literature review. Journal of Multi-Criteria Decision Analysis, 11(4-5):167-186. 